\title{
New and Re-new: Expanding Prevention Science within Child and Adolescent Health
}

\author{
Susan R. Tortolero • Dennis H. Li
}

Published online: 11 February 2012

(C) Springer Science+Business Media, LLC 2012

In this issue of the Journal of Primary Prevention, we address some emerging issues in child and adolescent health as well as explore established concepts in new contexts. The first two articles highlight the fast changing field of child and adolescent health and the need for researchers to keep pace with this phase of life and the changing social, cultural, and environmental landscape. For example, the dietary supplement industry has had tremendous growth in the last decade (Nutrition Business Journal, 2011), but few have examined how supplements impact youth. Evans and colleagues studied real-world use of dietary supplements that is not captured in clinical trial studies. They report that $5.5 \%$ of children and adolescents in the US used herbal supplements, and $4.4 \%$ used vitamin supplements in the past 30 days to improve sports performance. While these percentages are relatively small, it is estimated that over a million youth used supplements to enhance sports performance. This article emphasizes the need for further research, given the lack of evidence of the efficacy and safety of performance-enhancing supplements for youth.

Another emerging adolescent health concern highlighted in this issue is the use of the Internet to meet

S. R. Tortolero $(\bowtie) \cdot$ D. H. Li $(\bowtie)$

University of Texas School of Public Health,

Houston, TX, USA

e-mail: Susan.Tortolero@uth.tmc.edu

D. H. Li

e-mail: Dennis.H.Li@uth.tmc.edu sex partners. Whiteley et al. examined a population of sexually active, African American youth to determine the frequency of meeting sex partners through the Internet and whether those who met sex partners online exhibited greater risk behaviors than those who did not engage in this activity. Their findings show that $6 \%$ of African American youth reported meeting sex partners online and that those who used the Internet to meet sex partners were more likely to engage in highrisk behaviors such as drug use at last sex, marijuana and cocaine use, and unprotected vaginal and anal sex. This study highlights a population that may be at higher risk for unintended pregnancy, HIV, and other STIs but also study points to an opportunity to access high-risk populations through the Internet for intervention purposes.

The next three articles take concepts familiar to child and adolescent health and apply them within new contexts. Knowlden and coauthors examined whether constructs from the theory of planned behavior would be useful in predicting sleep intentions among college students attending a Midwestern university. Increasing evidence suggests the prevalence of sleep deprivation is on the rise, particularly in this population (Bixler, 2009; Lund, Reider, Whiting, \& Prichard, 2010). Sleep deprivation has been reported to be associated with poor health, increased risk of injury, and decreased performance (for example, Ayas et al., 2003; Lockley et al., 2004; Stickgold, Hobson, Fosse, $\&$ Fosse, 2001). The study by Knowlden and colleagues suggests the theory of planned behavior may 
be useful in designing prevention programs to address sleep deprivation in college students.

Another well-established determinant of health for adolescents is social support, but research on Latino populations outside the United States is limited. Reininger and colleagues assessed perceived social support and community empowerment among a large sample of urban middle school students in Matamoros, Mexico, and examined their association to fighting, alcohol and tobacco use, and sexual activity. Their data indicate perceived lack of parent and teacher support is associated with risk behaviors among girls but not boys; however, risk behaviors were associated with a perceived lack of empowerment among boys but not girls. These findings may have implications for tailoring interventions for boys and girls in this Mexican population.

Lastly, mentoring has long been used as a component in many interventions for youth, but research into the details of the mentor-mentee relationship is still emerging. Using a prospective mixed-methods design, Keller and Pryce inductively categorized mentoring experiences into four patterns. They report not only that sage/counseling-type relationships were rated most favorably by mentees but also that students involved in this type of mentoring showed statistically significant decreases in depressive symptoms and aggressive behaviors. In contrast, students in acquaintance-type relationships demonstrated some increases in depressive symptoms and aggression. This study suggests further examination into the quality of mentor-mentee relationships and the addition of mentor support or training to mentoring programs may be needed.
These five articles are an example of the growing body of knowledge behind child and adolescent health. Whether exploring new issues that arise with changing technologies or refining and adapting fundamental concepts, continued research is critical to move the field of primary prevention forward.

\section{References}

Ayas, N. T., White, D. P., Manson, J. E., Stampfer, M. J., Speizer, F. E., Malhotra, A., et al. (2003). A Prospective study of sleep duration and coronary heart disease in women. Archives of Internal Medicine, 163(2), 205-209. doi:10.1001/archinte.163.2.205.

Bixler, E. (2009). Sleep and society: An epidemiological perspective. Sleep Medicine, 10(Supplement 1), S3-S6. doi: 10.1016/j.sleep.2009.07.005.

Lockley, S. W., Cronin, J. W., Evans, E. E., Cade, B. E., Lee, C. J., Landrigan, C. P., et al. (2004). Effect of reducing interns' weekly work hours on sleep and attentional failures. New England Journal of Medicine, 351(18), 1829-1837. doi:10.1056/NEJMoa041404.

Lund, H. G., Reider, B. D., Whiting, A. B., \& Prichard, J. R. (2010). Sleep patterns and predictors of disturbed sleep in a large population of college students. Journal of Adolescent Health, 46(2), 124-132. doi:10.1016/j.jadohealth.2009. 06.016.

Nutrition Business Journal. (2011). NBJ's supplement business report: An analysis of markets, trends, competition and strategy in the U.S. dietary supplement industry. Retrieved from http://newhope360.com/2010-supplement-businessreport- 0 .

Stickgold, R., Hobson, J. A., Fosse, R., \& Fosse, M. (2001). Sleep, learning, and dreams: Off-line memory reprocessing. Science, 294(5544), 1052-1057. doi:10.1126/science. 1063530 . 